\title{
Care Report
}

\section{A combined Surgical-Orthodontic treatment in skeletal Class II malocclusion patients}

\author{
Dipjyothi Baruah ${ }^{1}$, Amit Rekhawat ${ }^{2}$, Karthik Cariappa ${ }^{3}$, Prathyaksha Shetty ${ }^{4, *}$, \\ Sujala Ganapati Durgekar ${ }^{4}$, Anup Belludi ${ }^{4}$, Aravind $\mathbf{M}^{4}$ \\ ${ }^{1}$ Dept. of Orthodontics, Pearly White Multispeciality Dental Clinic and Orthodontic Centre, Mangaldoi, Assam, India \\ ${ }^{2}$ Dept. of Orthodontics, Siddharth Arcade,8A, Mohini Mohan Road, Kolkata, West Bengal, India \\ ${ }^{3}$ Hayes dental,11/1 Hayes Road, Richmond Town, Bengaluru, Karnataka, India \\ ${ }^{4}$ Dept. of Orthodontics and dentofacial Orthopedics, K.L.E. Society's Institute of Dental Sciences, Bengaluru, Karnataka, India
}

\section{A R T I C L E I N F O}

\section{Article history:}

Received 28-06-2021

Accepted 10-08-2021

Available online 20-08-2021

\section{Keywords:}

Skeletal Class II malocclusion

Mandibular retrognathism

Bilateral sagittal split osteotomy

Mandibular advancement

\begin{abstract}
A B S T R A C T
Skeletal Class II malocclusion with mandibular deficiency is one of the most common problems that patients seek treatment. Adult patients with severe skeletal Class II malocclusion need orthognathic surgery for successful treatment. Bilateral sagittal split osteotomy (BSSO) is the most often preferred technique for these patients. This case report briefs about two male patient of age 24 years presented with Class II Skeletal relation, mesoprosopic facial form, horizontal growth pattern and Angle's Class II div 1 malocclusion who were treated with Bilateral sagittal split osteotomy (BSSO) mandibular advancement. The ideal anteroposterior relation was established along with a Class I molar, incisor, canine relationship and ideal overjet, overbite and the overall facial esthetics were significantly improved. Combined surgicalorthodontic treatment aims to obtain a more harmonious facial, skeletal, dental and soft tissue relationship with an added patient self esteem.
\end{abstract}

This is an Open Access (OA) journal, and articles are distributed under the terms of the Creative Commons Attribution-NonCommercial-ShareAlike 4.0 License, which allows others to remix, tweak, and build upon the work non-commercially, as long as appropriate credit is given and the new creations are licensed under the identical terms.

For reprints contact: reprint@ipinnovative.com

\section{Introduction}

Skeletal Class II malocclusion with mandibular deficiency is one of the most common problems that patients seek treatment. ${ }^{1}$ Class II malocclusion in India varies from $1.9 \%$ to $8.37 \% .^{2}$ Orthognathic surgery is a good treatment approach for patients with severe skeletal discrepancies beyond the reach of conventional orthodontic treatment to obtain a more harmonious facial, skeletal and soft tissue relationship as well as to improve occlusal function. Patients undergoing orthognathic surgery may experience psychosocial benefits and improve their self-confidence, facial image and social adaptation. ${ }^{3}$ This article which illustrates two case reports, shows the benefit of a team

\footnotetext{
* Corresponding author.

E-mail address: prathyakshashetty95@gmail.com (P. Shetty).
}

approach in correcting a Class II skeletal deformity by Bilateral sagittal split osteotomy (BSSO) with mandibular advancement.

\section{Case Reports}

\subsection{Case 1}

\subsubsection{Diagnosis and etiology}

A 24-year-old male patient, had a chief complaint of forwardly placed upper front teeth. Facial photographs showed a symmetric face, convex profile with a retruded chin, a proportionally short lower anterior facial height, potentially competent lip at rest, and a deep labiomental fold. He had a normal gingival tissue display when smiling. [Figure 1] 
Intraorally, he had Angle's Class II div 1 with a $7 \mathrm{~mm}$ overjet and a $4 \mathrm{~mm}$ overbite, mild crowding, dental midline matching. [Figure 2]

On cephalometric analysis the patient had class II skeletal pattern $\left(\mathrm{ANB}=6^{\circ}\right.$ ) with retruded mandible $\left(\mathrm{SNB}=77^{\circ}\right)$, horizontal growth pattern $\left(\mathrm{FMA}=22^{\circ}\right)$ and bidental proclination. [Table 1, Figure 3)

Table 1: Cephalometric analysis of case 1

\begin{tabular}{lccc}
\hline Parameters & $\begin{array}{c}\text { Pre- } \\
\text { Treatment }\end{array}$ & $\begin{array}{c}\text { Pre- } \\
\text { surgery }\end{array}$ & $\begin{array}{c}\text { Post- } \\
\text { debond }\end{array}$ \\
SNA & $83^{\circ}$ & $83^{\circ}$ & $83^{\circ}$ \\
SNB & $77^{\circ}$ & $76^{\circ}$ & $80^{\circ}$ \\
ANB & $6^{\circ}$ & $7^{\circ}$ & $3^{\circ}$ \\
Wits & $5 \mathrm{~mm}$ & $5 \mathrm{~mm}$ & $1 \mathrm{~mm}$ \\
F-M-A & $22^{\circ}$ & $22^{\circ}$ & $25^{\circ}$ \\
LAF ( Mc & $67 \mathrm{~mm}$ & $68 \mathrm{~mm}$ & $72 \mathrm{~mm}$ \\
Namara) & & & \\
UI - Palatal Plane & $115^{\circ}$ & $119^{\circ}$ & $118^{\circ}$ \\
UI - TVL & $-11 \mathrm{~mm}$ & $-11 \mathrm{~mm}$ & $-11 \mathrm{~mm}$ \\
IMPA & $108^{\circ}$ & $104^{\circ}$ & $102^{\circ}$ \\
Interincisal angle & $119^{\circ}$ & $122^{\circ}$ & $120^{\circ}$ \\
Tvl $\perp$ Chin & $-14 \mathrm{~mm}$ & $-14 \mathrm{~mm}$ & $-7 \mathrm{~mm}$ \\
\hline
\end{tabular}
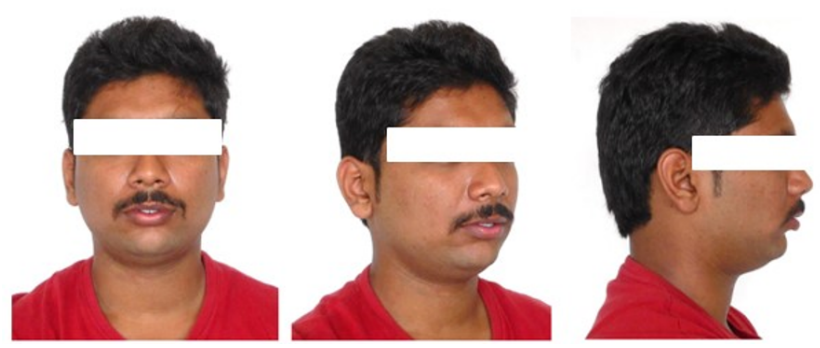

Fig. 1: Pre-treatment extra-oral photographs of case 1
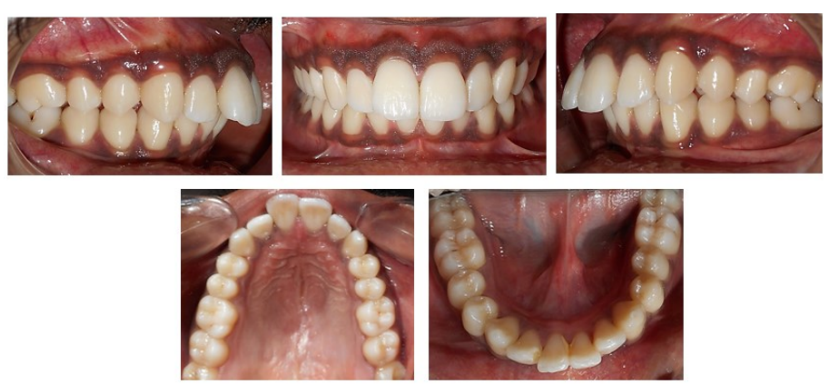

Fig. 2: Pre-treatmentintra-oral photographs of case 1

\subsubsection{Treatment objectives}

1. Correct the convex facial profile.

2. Resolve the dental crowding.

3. Establish normal overbite and overjet.

4. Achieve Class I molar and canine relation.

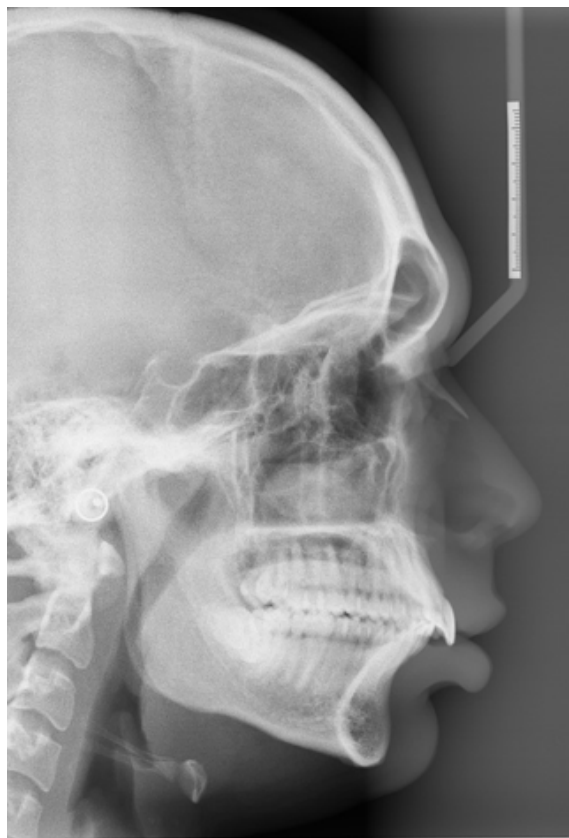

Fig. 3: Pre-treatment cephalograms of case 1

\subsubsection{Treatment alternatives}

1. Surgery first orthognathic approach followed by fixed mechanotherapy.

2. Surgical line of treatment with fixed mechanotherapy followed by mandibular advancement BSSO surgery.

3. Non-extraction line of treatment with fixed mechanotherapy and fixed functional appliance therapy.

\subsubsection{Treatment plan}

Surgical line of treatment with fixed mechanotherapy followed by mandibular advancement BSSO (Bilateral Sagittal split osteotomy) surgery. This plan was discussed with the patient considering the treatment objectives and correlating with the patient's requirements.

\subsection{Treatment progress}

\subsubsection{Pre-surgical phase}

Maxillary and mandibular arches were banded and bonded with 0.022" slot preadjusted MBT(McLaughlin, Bennett, and Trevisi) bracket prescription. Treatment progressed from levelling and alignment with $0.016^{\prime \prime} \mathrm{NiTi}, 0.018^{\prime \prime} \mathrm{SS}$, $0.019^{\prime \prime} \times 0.025^{\prime \prime} \mathrm{NiTi}, 0.021^{\prime \prime} \times 0.025^{\prime \prime} \mathrm{NiTi}$ and $0.021^{\prime \prime} \times$ $0.025^{\prime \prime}$ stainless steel wires. Presurgical records were taken, models were mounted using facebow transfer, mock surgery was done, and a surgical splint was fabricated.[Figures 4 and 5] 

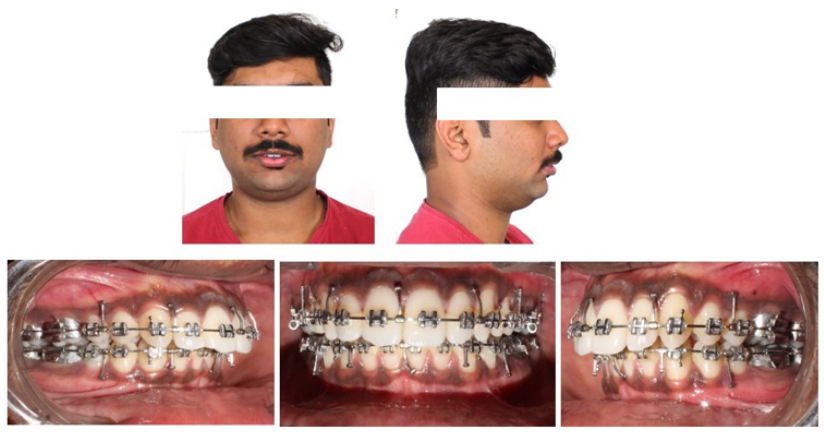

Fig. 4: Pre-surgical intra-oral and extra-oral photographs of case 1
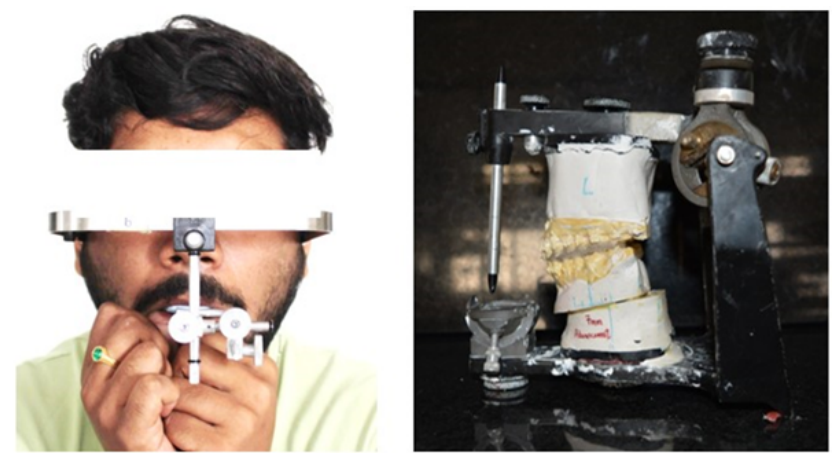

Fig. 5: Facebow transfer and mock-surgery photographs of case 1

\subsubsection{Surgical treatment}

BSSO (Bilateral Sagittal split osteotomy) with $7 \mathrm{~mm}$ of mandibular advancement was performed by an oral surgeon under general anesthesia. The osteotomy cuts were secured with titanium plates, surgical splint was placed in patient mouth and intermaxillary fixation was done for a period of 14 days.

\subsubsection{Post-surgical phase}

Finishing and detailing was done for 5 months, and debonding was done. An upper wraparound retainer and a lower fixed bonded lingual retainer were given. [Figures 6 and 7]
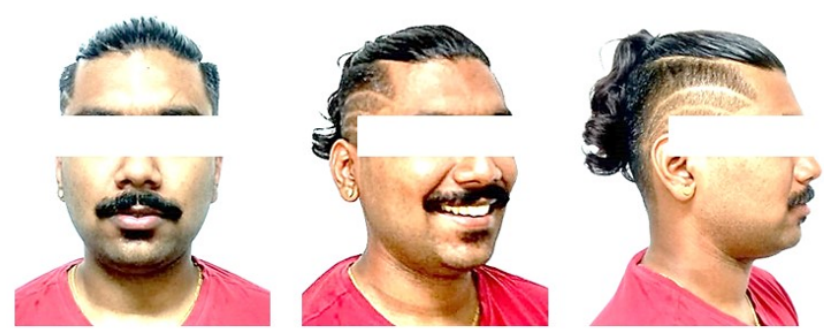

Fig. 6: Post-treatment extra-oral photographs of case 1

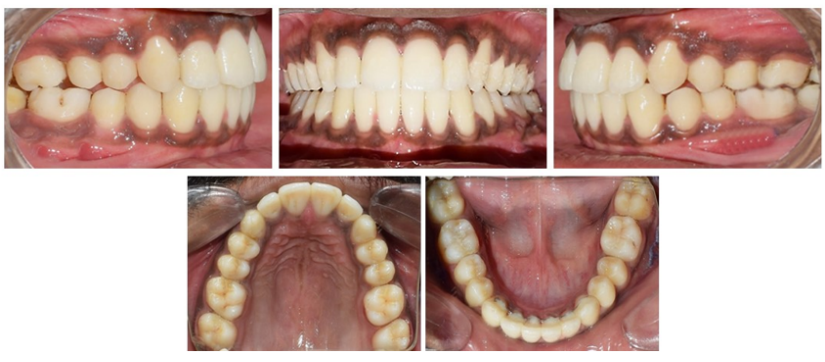

Fig. 7: Post-treatment intra-oral photographs of case 1

\subsection{Case 2}

\subsubsection{Diagnosis and Etiology}

A 24-year-old male patient, had a chief complaint of forwardly placed upper front teeth. Facial photographs showed a symmetric face, convex profile with a retruded chin, a proportionally short lower anterior facial height, potentially competent lip at rest, and a deep labiomental fold. He had a normal gingival tissue display when smiling. [Figure 8]

Intraorally, he had Angle's Class II Division 1 subdivision (right) malocclusion with proclined upper incisors, bidental crowding, increased overjet and deep overbite. [Figure 9]

On cephalometric analysis the patient had class II skeletal pattern $\left(\mathrm{ANB}=8^{\circ}\right.$ ) with retruded mandible $\left(\mathrm{SNB}=76^{\circ}\right)$, horizontal growth pattern $\left(\mathrm{FMA}=22^{\circ}\right)$ and bidental proclination. [Table 2, Figure 10]

Table 2: Cephalometric analysis of case 2

\begin{tabular}{lccc}
\hline Parameters & $\begin{array}{c}\text { Pre- } \\
\text { Treatment }\end{array}$ & $\begin{array}{c}\text { Pre- } \\
\text { surgery }\end{array}$ & $\begin{array}{c}\text { Pre- } \\
\text { finishing }\end{array}$ \\
SNA & $84^{\circ}$ & $84^{\circ}$ & $83^{\circ}$ \\
SNB & $76^{\circ}$ & $76^{\circ}$ & $80^{\circ}$ \\
ANB & $8^{\circ}$ & $8^{\circ}$ & $3^{\circ}$ \\
Wits & $6 \mathrm{~mm}$ & $5 \mathrm{~mm}$ & $1 \mathrm{~mm}$ \\
F-M-A & $22^{\circ}$ & $22^{\circ}$ & $25^{\circ}$ \\
LAF ( Mc & $56 \mathrm{~mm}$ & $57 \mathrm{~mm}$ & $59 \mathrm{~mm}$ \\
Namara) & & & \\
UI - Palatal Plane & $127^{\circ}$ & $123^{\circ}$ & $123^{\circ}$ \\
UI - TVL & $-8 \mathrm{~mm}$ & $-10 \mathrm{~mm}$ & $-10 \mathrm{~mm}$ \\
IMPA & $112^{\circ}$ & $102^{\circ}$ & $101^{\circ}$ \\
Interincisal angle & $100^{\circ}$ & $118^{\circ}$ & $118^{\circ}$ \\
Tvl $\perp$ Chin & $-13 \mathrm{~mm}$ & $-13 \mathrm{~mm}$ & $-8 \mathrm{~mm}$ \\
\hline
\end{tabular}

\subsubsection{Treatment objectives}

1. Correct the convex facial profile

2. Resolve the dental crowding,

3. Establish normal overbite and overjet, and

4. Achieve Class I molar and canine relation. 


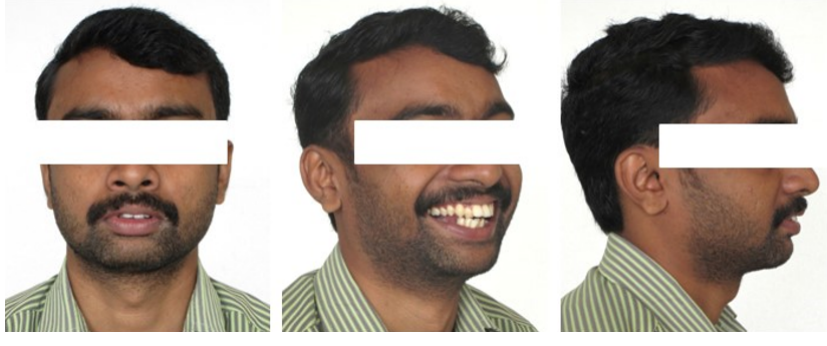

Fig. 8: Pre-treatment extra-oral photographs of case 2
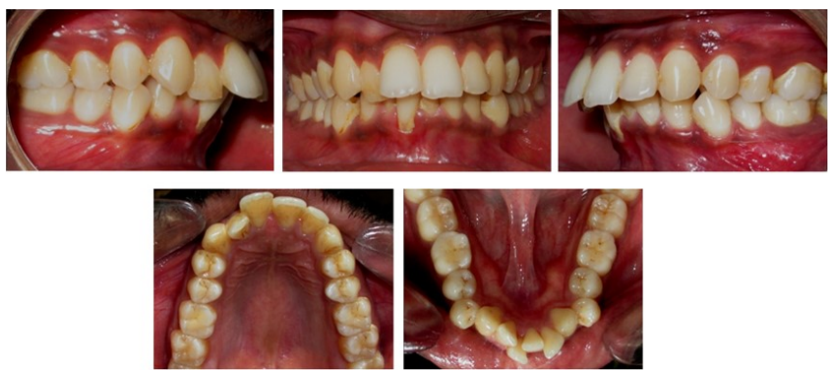

Fig. 9: Pre-treatment intra-oral photographs of case 2

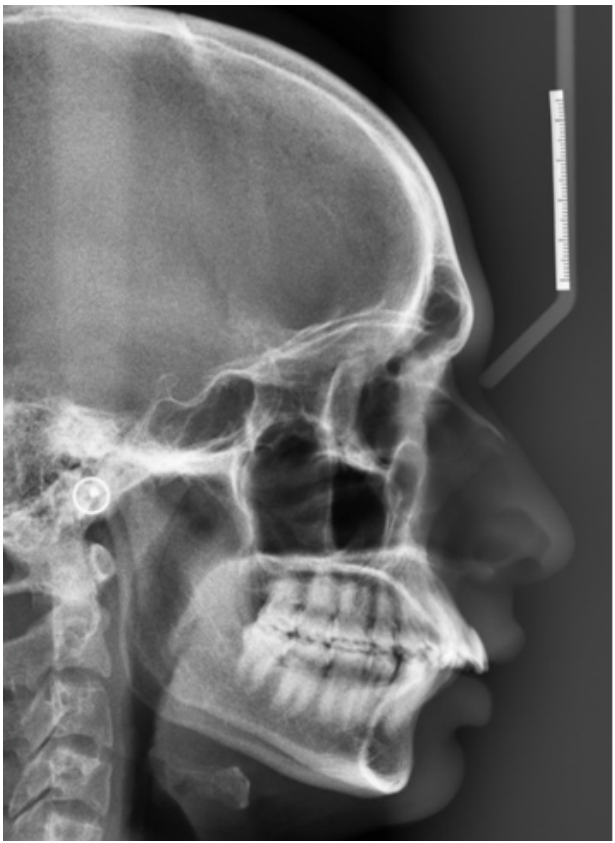

Fig. 10: Pre-treatment cephalograms of case 2

\subsubsection{Treatment plan}

Surgical line of treatment with extraction of maxillary second premolars and mandibular first premolars followed by mandibular advancement BSSO surgery.

\subsubsection{Treatment Progress}

Maxillary and mandibular arches were banded and bonded with $0.022^{\prime \prime}$ slot preadjusted MBT(McLaughlin, Bennett, and Trevisi) bracket prescription Treatment progressed from levelling and alignment with $0.016^{\prime \prime} \mathrm{NiTi}, 0.018^{\prime \prime} \mathrm{SS}$, $0.019^{\prime \prime} \times 0.025^{\prime \prime} \mathrm{NiTi}$ and $0.019^{\prime \prime} \times 0.025^{\prime \prime}$ stainless steel wires. Presurgical records were taken, models were mounted using facebow transfer, mock surgery was done, and a surgical splint was fabricated. [Figure 11] BSSO (Bilateral Sagittal split osteotomy) with $5 \mathrm{~mm}$ mandibular advancement was performed. Finishing and detailing was done for 5 months, and debonding was done after achieving the treatment goals. An upper and lower fixed bonded lingual retainer were given. [Figures 12 and 13]

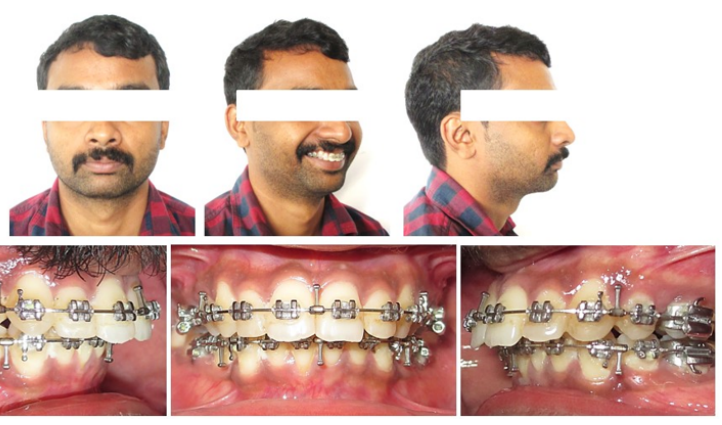

Fig. 11: Pre-surgical intra-oral and extra-oral photographs of case 2
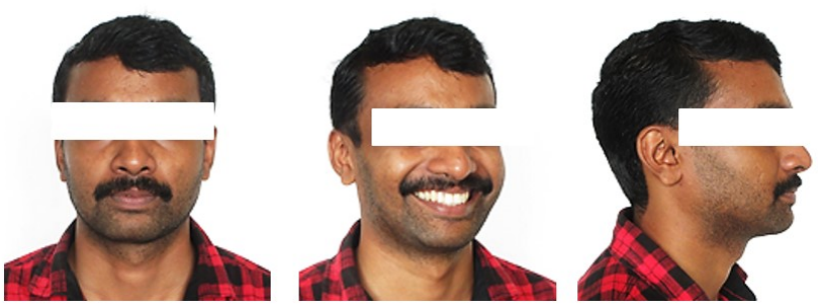

Fig. 12: Post-treatment extra-oral photographs of case 2

\section{Treatment Results}

In both the cases, the appraisal of the treatment outcomes showed a well aligned dentition where extra-orally, they demonstrated a pleasant smile and well-balanced facial profile and competent lips. Cephalometric evaluation [Figure 14a,b] and superimpositions [Figure 15a,b] confirmed an exemplary change in the profile and the case was finished in the Class I skeletal base. The intraoral 


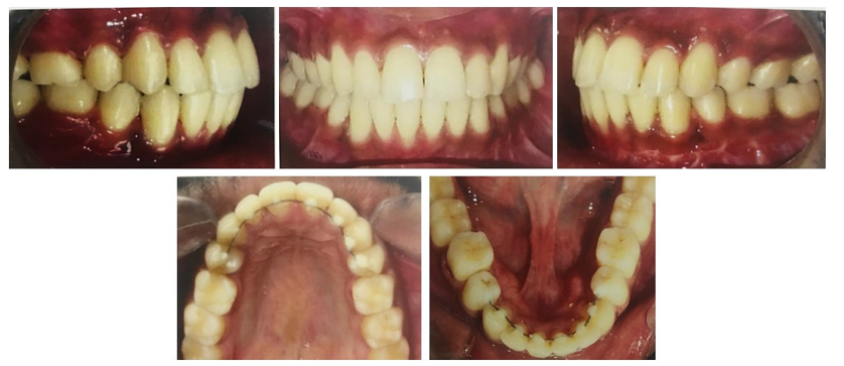

Fig. 13: Post-treatmentintra-oral photographs of case 2

photographs revealed a Class I molar, Class I canine and Class I incisor relationship on both the sides. Ideal and appropriate overjet and the overbite was achieved post-treatment. Total duration of time taken in both the cases were approximately 24 months.

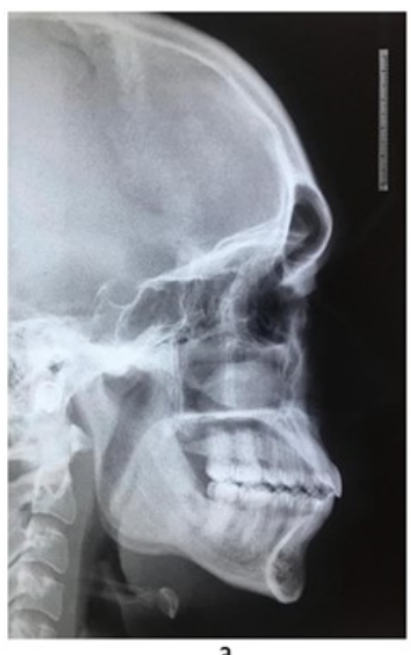

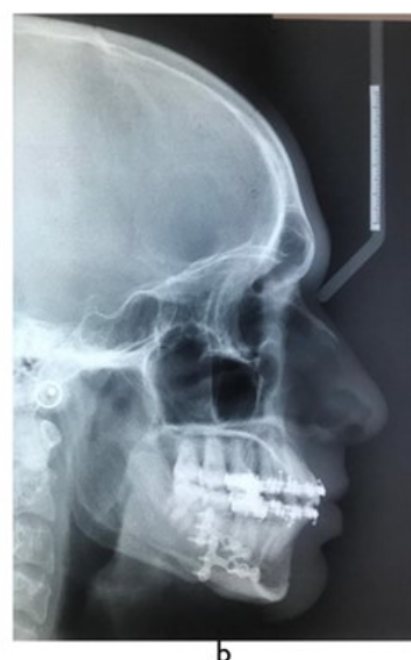

Fig. 14: Post-treatment cephalograms of case 1(14a) and case 2(14b)

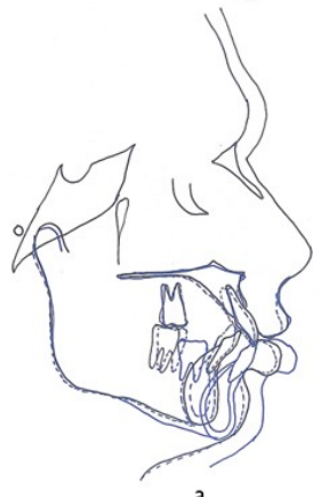

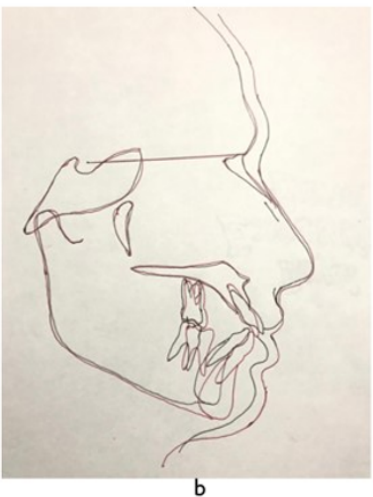

b
Fig. 15: Cephalometric superimposition of case 1(15a) and case 2(15b)

\section{Discussion}

The treatment of severe dentofacial deformities in adult patients is a challenging task for both orthodontist and oral surgeon because of the skeletal and facial disharmony, absence of jaw growth and a tendency to relapse. Camouflage treatment with skeletal discrepancy will be initiated with greater facial imbalance and this imbalance will either be maintained or deteriorated in value in relation to point $\mathrm{A}$, the upper incisor and the lower lip. ${ }^{4} \mathrm{BSSO}$ with advancements of up to $7 \mathrm{~mm}$ in patients with a low or normal MP-angle are considered stable with minimal long-term post-surgical skeletal relapse. ${ }^{5}$ Similarly in our cases, we opted for mandibular advancement not more than $7 \mathrm{~mm}$. Studies suggest that with mandibular advancement surgery, profiles of patients were observed to improve with a decrease in facial convexity, an increase in lower facial height, decrease depth of the mentolabial sulcus. In addition, lip competency will be improved, which is agreeable with results of our cases. ${ }^{6}$

During the pre-surgical orthodontic treatment, the opposite of camouflage treatment is performed dentally where decompensation is achieved by moving teeth to a proper functional position relative to the skeletal bases. ${ }^{7}$ During this phase of treatment, generally, the goal is to eliminate the dental interferences for the ideal correction of existing skeletal discrepancies. ${ }^{8}$ In our first case, decompensation was performed with non-extraction protocol whereas in the second case, decompensation was done by extraction of premolars due to presence of moderate crowding in arches

\section{Conclusion}

A skeletal Class II malocclusion treated with proper diagnosis and treatment planning improves the esthetic value of the patient. Inter-disciplinary approach favoured in the successful management of a patient with mandibular advancement (BSSO) to achieve superior function, stability, facial esthetics, an ideal occlusion and also provided good postoperative stability.

\section{Conflict of Interest}

The authors declare that there are no conflicts of interest in this paper.

\section{Source of Funding}

None.

\section{References}

1. Mcneill RW, West RA. Severe mandibular retrognathism: Orthodontic versus surgical orthodontic treatment. Am J Orthod. 1977;72(2):17682. do1:10.1016/0002-9416(77)90058-6. 
2. Kaur H, Pavithra US, Abraham R. Prevalence of malocclusion among adolescents in South Indian. J Int Soc Prev Comm Dent. 2013;3(2):97102.

3. Hodge TM, Boyd PT, Munyombwe T, Littlewood SJ. Orthodontists' perceptions of the need for orthognathic surgery in patients with Class II Division 1 malocclusion based on extraoral examinations. Am J Orthod. 2012;142(1):52-9. do1:10.1016/].ajodo.2012.02.020.

4. Demir A, Uysal T, Sari Z, Basciftci F. Effects of camouflage treatment on dentofacial structures in Class II division 1 mandibular retrognathic patients. Eur J Orthod. 2005;27(5):524-31. doi:10.1093/ejo/cji046.

5. Mobarak KA, Espeland L, Krogstad O, Lyberg T. Mandibular advancement surgery in high-angle and low-angle class II patients: Different long-term skeletal responses. Am J Orthod Dentofacial Orthop. 2001;119(4):368-81.

6. Uppada UK, Sinha R, Ann PD. Soft tissue changes and its stability as a sequlae to mandibular advancement. Maxillofac Surg. 2014;4(2):1327.

7. Arnett GW, Mclaughlin RP. Facial and dental planning for orthodontists and oral surgeons. Elsevier Limited; 2004. p. 261-3.

8. Altay B, Eraydın F, DirenEsener S, Ülkür E. Patient with Severe Skeletal Class II Malocclusion: Double Jaw Surgery with Multipiece Le Fort I. Turk J Orthod. 2018;31(3):95-102. dol:0.5 $52 /$ TurkJorthod2018.7039.

\section{Author biography}

Dipjyothi Baruah, Clinical Practitioner

Amit Rekhawat, Clinical Practitioner

Karthik Cariappa, Clinical Practitioner

Prathyaksha Shetty, Post Graduate Student

Sujala Ganapati Durgekar, Reader

Anup Belludi, Professor

Aravind M, Reader

Cite this article: Baruah D, Rekhawat A, Cariappa K, Shetty $\mathrm{P}$, Durgekar SG, Belludi A, Aravind M. A combined Surgical-Orthodontic treatment in skeletal Class II malocclusion patients. J Dent Panacea 2021;3(2):82-87. 